\title{
Guidance on research integrity provided by European discipline-specific learned societies: A scoping review
}

Rosie Hastings ${ }^{*}$, Krishma Labib $^{\dagger}$, Iris Lechner ${ }^{\ddagger}$, Lex Bouter ${ }^{\S}$, Guy Widdershoven ${ }^{* *}$, Natalie Evans ${ }^{\dagger \dagger}$ on behalf of the EnTIRE consortium

\footnotetext{
* MA student, research assistant. Amsterdam UMC, Vrije Universiteit Amsterdam, Department of Ethics, Law and Humanities, Amsterdam Public Health Institute, De Boelelaan 1117, 1081HV, Amsterdam, the Netherlands

$\dagger$ PhD candidate. Amsterdam UMC, Vrije Universiteit Amsterdam, Department of Ethics, Law and Humanities, Amsterdam Public Health Institute, De Boelelaan 1117, 1081HV, Amsterdam, the Netherlands

* PhD candidate. Vrije Universiteit Amsterdam, Department of Philosophy, Faculty of Humanities, De Boelelaan 1105, 1081HV Amsterdam, The Netherlands

$\S$ Professor of Methodology and Integrity. Vrije Universiteit Amsterdam, Department of Philosophy, Faculty of Humanities, De Boelelaan 1105, 1081HV Amsterdam, The Netherlands, and Amsterdam University Medical Centers, Department of Epidemiology and Data Science, Amsterdam Public Health Institute, De Boelelaan 1117, 1081HV, Amsterdam, the Netherlands

** Emeritus Professor of Medical Philosophy and Ethics. Amsterdam UMC, Vrije Universiteit Amsterdam, Department of Ethics, Law and Humanities, Amsterdam Public Health Institute, De Boelelaan 1117, 1081HV, Amsterdam, the Netherlands

$\dagger$ Assistant Professor. Amsterdam UMC, Vrije Universiteit Amsterdam, Department of Ethics, Law and Humanities, Amsterdam Public Health Institute, De Boelelaan 1117, 1081HV, Amsterdam, the Netherlands Correspondence to: n.evans@ amsterdamumc.nl, T: +31.20.4448218
} 


\begin{abstract}
There is little research on how guidance provided in the European Code of Conduct for Research Integrity (ALLEA code) compares with recommendations developed by European discipline-specific learned societies. We identified, and conducted a content analysis of, 58 guideline documents from 245 societies.

Less than $25 \%$ of societies in any discipline provide guidance and there are notable disciplinary differences. Recommendations not reflected in the ALLEA code relate primarily to research culture and environment. Medical and Health Sciences societies often focus on regulatory and procedural aspects of research, whereas Natural Sciences societies emphasize the importance of accurate and appropriate dissemination of results. Humanities and Social Sciences societies' recommendations are more heterogenous and relate to the nature of specific sub-disciplines. Our results reflect differences in epistemological approaches as well as the specific role and responsibilities of societies as membership organizations. We recommend that societies develop, or endorse, appropriate research integrity guidance.
\end{abstract}

Key words: research integrity, research ethics, responsible conduct of research, science policy, open science 


\section{INTRODUCTION}

In response to concerns regarding the replication crisis $(1,2)$ and the high prevalence of research misconduct and questionable research practices (3-6), research integrity (RI) has increasingly become a focus for the research community (7-11). Although no universally accepted definition of RI exists (12), it is commonly understood "to relate to the performance of research to the highest standards of professionalism and rigor, in an ethically robust manner" (13). Conducting research with integrity is seen by many to ensure the reliability of research output by improving validity, robustness and accuracy, whilst taking normative considerations, such as honesty (for example, in acknowledging financial contributions and reporting findings), into account, thus improving trustworthiness $(13,14)$.

Much of the current guidance on RI is based on the idea that the research community - i.e. those involved in research directly, such as researchers, or indirectly, such as research performing organisations, funding agencies and scholarly journals - can, should, and will self-regulate (13). Indeed, notable efforts have been made by the research community to provide a cohesive framework for self-regulation, for example, in the form of the European Code of Conduct for Research Integrity published by All European Academies (ALLEA) (15), referred to hereinafter as the ALLEA code. The ALLEA code states that the principles and practices it endorses are applicable for all "[r]esearchers, academies, learned societies, funding agencies, public and private research performing organisations, publishers and other relevant bodies" at the local and national levels (15). As such, the ALLEA code is intended to apply to all research. This is a broad scope, considering that research concerns the generation of knowledge about specific phenomena via the collection, analysis and interpretation of data or systematic thinking $(15,16)$. In line with this, research traditions are diverse in terms of their theoretical and methodological approaches and are based on different epistemological frameworks (17).

It is unclear if the ALLEA code's generalized approach to RI adequately reflects ideas about RI across disciplines. Indeed, the majority of efforts to promote RI originate from the biomedical and social sciences, with fewer initiatives coming from the natural sciences and humanities (18). Ideas about RI, however, are at least partly shaped by the distinct principles and standards within disciplines. For example, open science practices associated with replicability and verifiability (such as open methods, open codes and open data) are seen as gold standards for research in much of the natural and medical and health sciences, as well as some social sciences (e.g. psychology), but the relevance of these practices for the humanities and other social sciences (e.g. philosophy or anthropology), remains a matter of debate (19-21).

Considering the emphasis in RI on adhering to 'professional standards', guidance provided by learned societies - organised groups of professionals, academics, and students with an affiliation to a particular discipline - can provide insight into discipline-specific conceptions of RI. The purpose of our research is three-fold. Firstly, we aim to assess the frequency and distribution of guidance on RI from European learned societies across disciplines. Secondly, we aim to compare societies' RI guidance with the ALLEA code to determine whether guidance from specific disciplines is consistent with the ALLEA code. Thirdly, we aim to highlight the similarities and differences between societies' guidance to assess how RI is conceptualised and operationalised across disciplines.

\section{METHODS}

The study is designed according to the PRISMA extension for scoping reviews (22). This reporting guideline is appropriate because we aim to assess the scope of available literature on RI across discipline-specific learned societies in Europe and synthesize this evidence (22). A preregistered review protocol is available at https://osf.io/s8aez?view_only=c481f48c07e64a789bad6876a2092bf7. 


\section{Search Strategy}

To identify relevant documents providing guidance on RI from European discipline-specific learned societies, a three-part search strategy was developed in consultation with a clinical librarian (see acknowledgements).

\section{Part 1 - Literature relating to societies' codes of conduct (CoCs)}

Published and grey literature database searches aimed to retrieve research-related CoCs from societies (details of the search terms and databases used can be found in Supplementary File 1).

Details of the inclusion criteria can be found in Table 1. Articles were retrieved, duplicates removed, and records screened on title and abstract. Full-text articles were assessed for eligibility if titleabstract screening was insufficient to decide on inclusion. A sub-sample $(45 \%, \mathrm{n}=213)$ of records were independently screened by a second screener (NE or KL) and any disagreements were discussed until consensus was reached. The names of societies were extracted from included articles and added to the overview compiled in Part 2, below.

\section{Part 2 - An overview of societies}

An overview of societies was compiled from (1) those identified in part 1, (2) those contained in a stakeholder list from the Initiative for Science in Europe (accessed in 2017 for a different project from https://initiative-se.eu/, no longer available on the ISE website), (3) a Wikipedia list of European learned societies (accessed May 2020 from

https://en.wikipedia.org/wiki/List of learned societies\#European), and (4) a Google search for societies (performed in February 2021, details of the search term used can be found in Supplementary File 1). Duplicates were removed, societies were assessed for eligibility against the inclusion criteria shown in Table 1, and were categorised by discipline (e.g. Natural Sciences, Social Sciences) and subdiscipline (e.g. mathematics, psychology) according to the OECD research areas (23). A sub-sample $(41 \%, n=144)$ were independently screened by a second screener (NE, KL or IL) and any disagreements regarding inclusion or categorisation were discussed until consensus was reached.

\section{Part 3 - Societies' guidance}

The websites of societies included in the overview compiled in part 2 were identified (Supporting data file 1, available at: https://osf.io/u $7 \mathrm{kq} 4 /$ ) and manually searched for potentially relevant documents by 2 researchers (RH and IL). Details of the inclusion criteria can be found in Table 1. During the search process, it became apparent that relevant guidance on RI is not only to be found in a $\mathrm{CoC}$ but may be contained across a number of other documents, such as guidelines, statements, or reports. In order to recognize the existence of this guidance we broadened the document inclusion criteria (Table 1). All potentially relevant documents describing RI principles and/or standards were retrieved and subsequently assessed for eligibility for inclusion. All documents were independently screened by a second screener (NE or KL) and any disagreements were discussed until consensus was reached. 


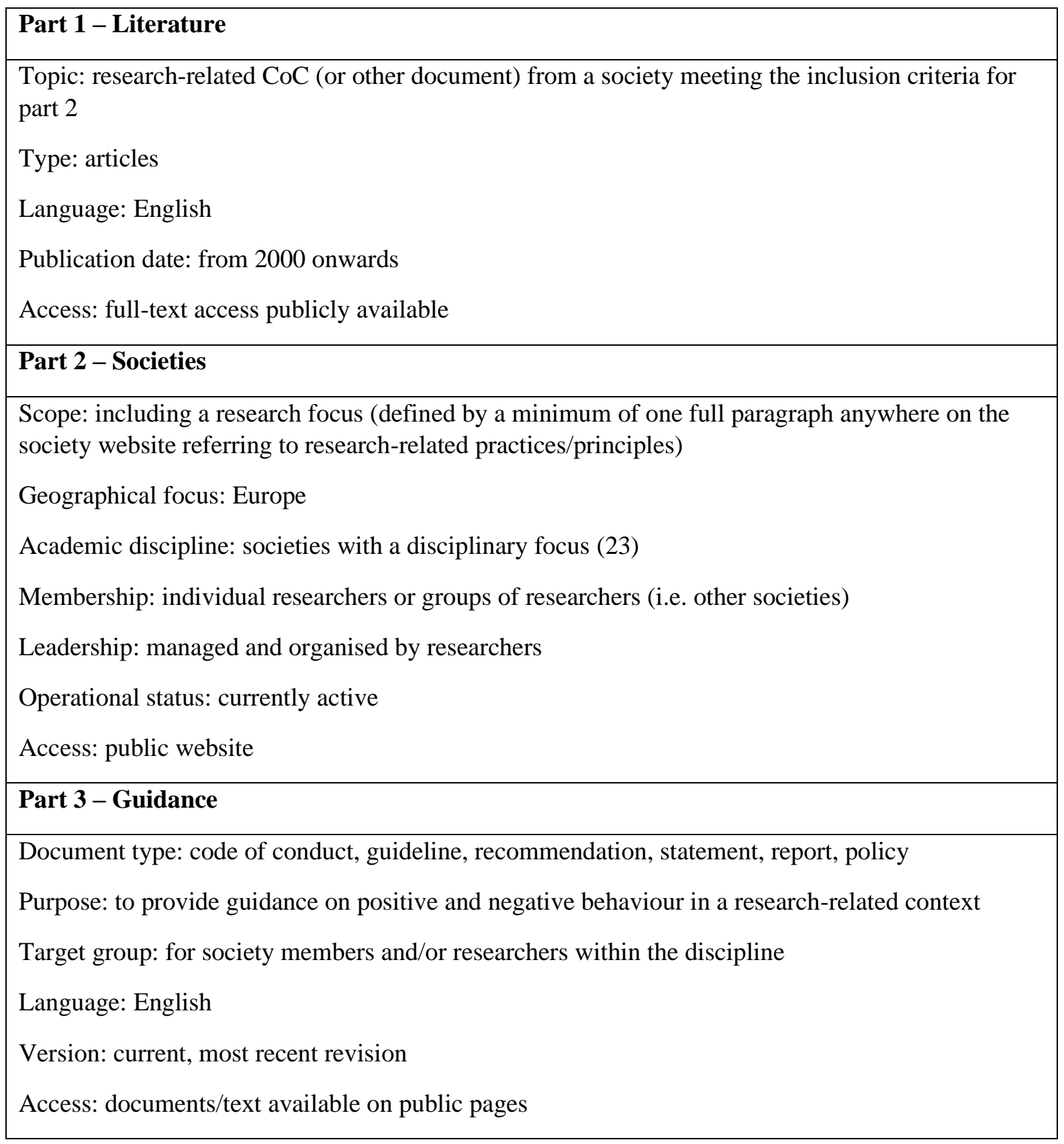




\section{Data charting}

For each society, we recorded whether the society website contained documents that met the inclusion criteria (Supporting data file 1, available at: https://osf.io/u $7 \mathrm{kq} 4 /$ ). A data extraction table of included documents was created in which the following document attributes, if available, were recorded (Supporting data file 2, available at: https://osf.io/y9qps/):

1. Title (recorded verbatim)

2. Website link to document

3. Name of society that developed and disseminated the document

4. Discipline of the society, according to the OECD research areas (23)

5. Publication date of the most recent version (if clear)

6. Document type (CoC, guideline, recommendation, statement, report, policy - based on document title)

\section{Content analysis}

The ALLEA code and societies' guidance documents were analysed using a qualitative content analysis following a mixed deductive-inductive approach (24). All content was coded by a first (RH) and second (NE, KL, or IL) coder. Discrepancies in coding were listed and each item of disagreement was discussed between coders until agreement was reached.

\section{Analysis of the ALLEA code and development of the coding scheme}

We first inductively open coded the ALLEA code, which resulted in codes related to 'Principles', 'Practices', and 'Responsible parties'. 'Principles' were propositions or values which guide conduct, 'Practices' referred to specific descriptions of types of research conduct, and 'Responsible parties' referred to specific individuals or groups who were recommended to adhere to or uphold a certain principle or practice. Principles were coded as any explicit mention of aspirational values prescribed by the code, according to the exact words used in the text. Specific practices were either recommended or described as unacceptable; unacceptable behaviours were grouped into one main category, 'Misconduct, mistakes and unacceptable practices'.

The coding scheme developed from the analysis of the ALLEA code then served as our deductive coding scheme for the next steps of the analysis. Four coders (RH, NE, KL, IL) collaboratively developed the coding scheme (Supplementary File 2).

\section{Analysis of societies' guidance}

Societies guidance was line-by-line coded using the deductive coding scheme. The sampling units were guidance documents, while context units were the sections within these dedicated to RI, and recording units were the areas of text coded. The initial preliminary coding scheme, developed from analysis of the ALLEA code, was further developed through inductive coding of additional principles, practices, and responsible parties represented in societies' guidance. New codes were developed by both the first coder ( $\mathrm{RH}$ ) and second coders (NE, KL, IL). The appropriateness of new codes was discussed in team meetings and the coding scheme was developed and adapted iteratively to reflect new codes and the merging of other codes.

Within the three over-arching categories ('Principles', 'Practices' and 'Responsible parties'), codes were grouped into main categories and sub-categories (e.g. 'Planning and performing research' is a sub-category of 'Research performance, publication, review and dissemination', which is a main category of 'Practices') which best reflected their manifest content, avoiding overlap as much as possible. To accommodate for all practices discussed across both the ALLEA code and societies' guidance, fewer main categories, but with more sub-categories, are presented here than in the ALLEA 
code - 5 main categories are used, as opposed to the 8 "contexts" in the ALLEA code (15). Main categories and sub-categories were also discussed and refined in team meetings. These are described in detail in the results section with particular attention paid to differences found between the ALLEA code and guidance from societies, and between guidance from societies of different disciplines.

Once categorisation was complete, we conducted a within case analysis of the guidance documents to examine differences in the categories between disciplines (24). In addition to the qualitative content analysis, frequencies of the occurrence of codes relating to principles, practices and responsible parties mentioned in societies' guidance, and in the ALLEA code, are reported for each discipline.

\section{RESULTS}

\section{Inclusion}

\section{Part 1 - Literature relating to societies' CoCs}

The results of the literature search are presented in a PRISMA flow diagram (Figure 1) (25). A total of 687 records were retrieved, with 468 remaining after de-duplication. Of these, 54 articles met the inclusion criteria, from which we identified 77 societies (multiple societies were mentioned in some articles) to add to our list described in part 2, below.

\section{Part 2 - An overview of societies}

The Initiative for Science in Europe and Wikipedia lists contained 147 and 11 societies, respectively, and the Google search returned 228 societies. Following de-duplication of the complete list of 463 societies (including the 77 societies identified in part 1), 347 societies remained. Each society was considered for eligibility based on an assessment of the information available on their website (if the website was not accessible the society was excluded), resulting in a final list of 245 European discipline-specific learned societies.

\section{Part 3 - Societies' guidance}

The website of each included society was manually checked by two independent assessors (RH and either IL, KL or NE) to identify relevant RI guidance. A combined list of 163 documents was screened and assessed for eligibility, resulting in the selection of 58 relevant documents to be included in the content analysis. Documents that were not related to research (e.g. society bylaws) were excluded (a full list of exclusion reasons is available at: https://osf.io/pxsuj/). 


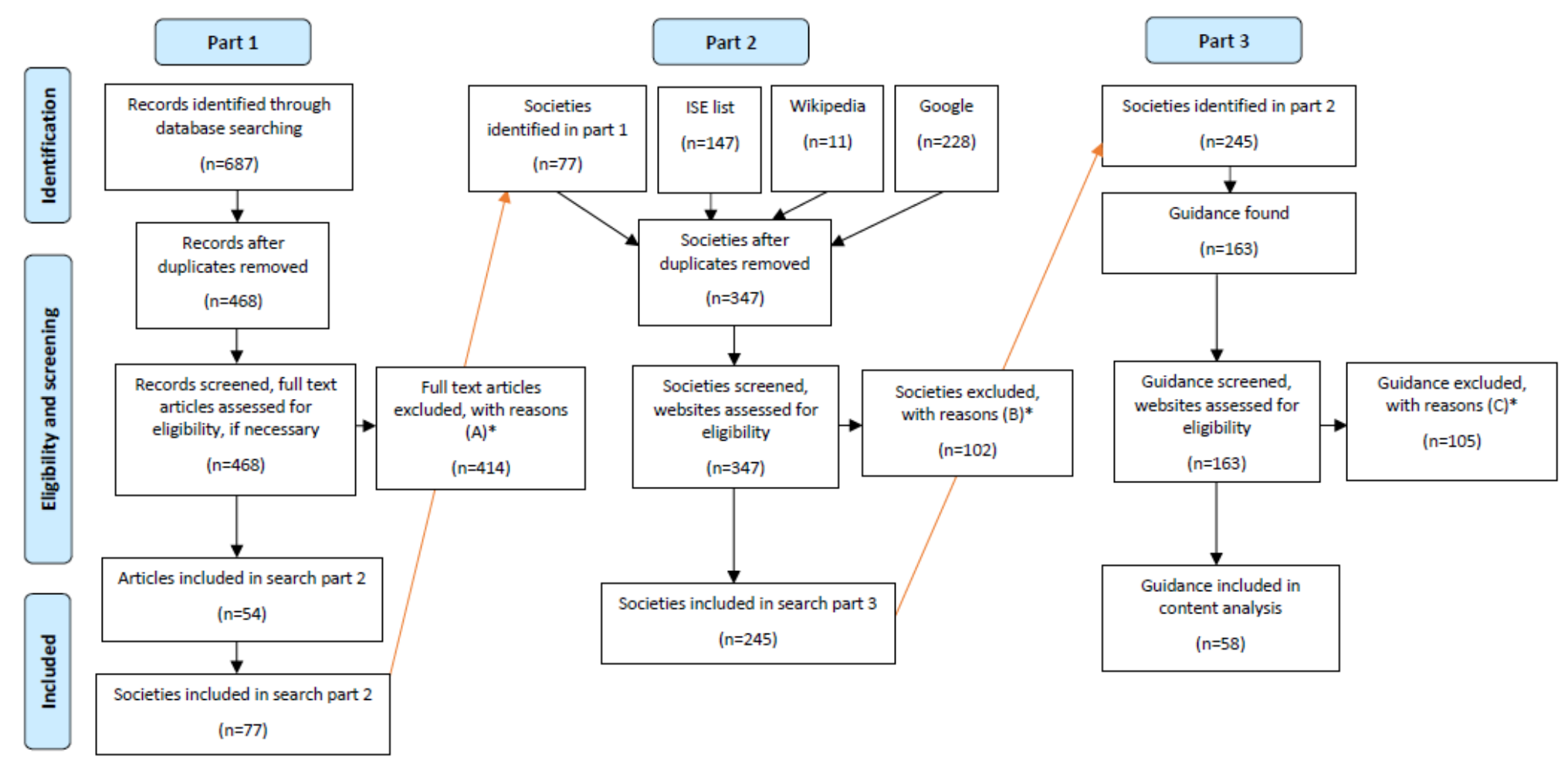

From: Moher D, Liberati A, Tetzlaff J, Altman DG, The PRISMA Group (2009). Preferred Reporting ftems for Systematic Reviews and Meta-Analyses: The PRISMA Statement. PLoS Med 6(7): e1000097. doi:10.1371/journal.pmed1000097

For more information, visit www.prisma-statement.ors.

Figure 1: Adapted PRISMA flowchart showing the complete search process. Orange arrows indicate the links between each part of the search. Part 1 (left column) refers to the literature database search which made up the initial stage of the search for societies. Part 2 (middle column) refers to additional steps in the search for societies. Part 3 (right column) refers to the search of included societies' websites for RI guidance documents.

*See lists (A), (B), and (C), available at: https://osf.io/pxsujl, for exclusion reasons for articles (part 1), societies (part 2) and guidance (part 3), respectively. 


\section{Availability of guidance across disciplines}

Of the final list of 245 European discipline-specific learned societies, 54 societies made relevant RI guidance available. Forty-six of these societies had developed their own guidance (Figure 2 ), while 16 referred to guidance developed by another society or organization, eight of which had both self-developed guidance as well as referring to external guidance, including one society (European Association for Personality Psychology) that referred to the ALLEA code (see Supporting data file 3, available at: https://osf.io/x925z/, for a complete list of guidance referred to). The majority of societies therefore provided no self-developed guidance on RI $(n=199)$.

Of the 46 societies that developed their own guidance, there were distinct disciplinary differences; $25 \%$ of Social Sciences societies, $24 \%$ of Medical and Health Sciences societies, $16 \%$ of Natural Sciences societies, $12 \%$ of Humanities societies and 5\% of Engineering and Technology societies provided relevant guidance (Figure 2). No guidance was provided by Agricultural Sciences societies. Due to the small number of Humanities societies for which relevant guidance was found $(n=2)$, this is discussed together with guidance from Social Sciences societies (Humanities and Social Sciences) throughout. For the same reason, the Engineering and Technology society has been grouped with the Natural Sciences societies.

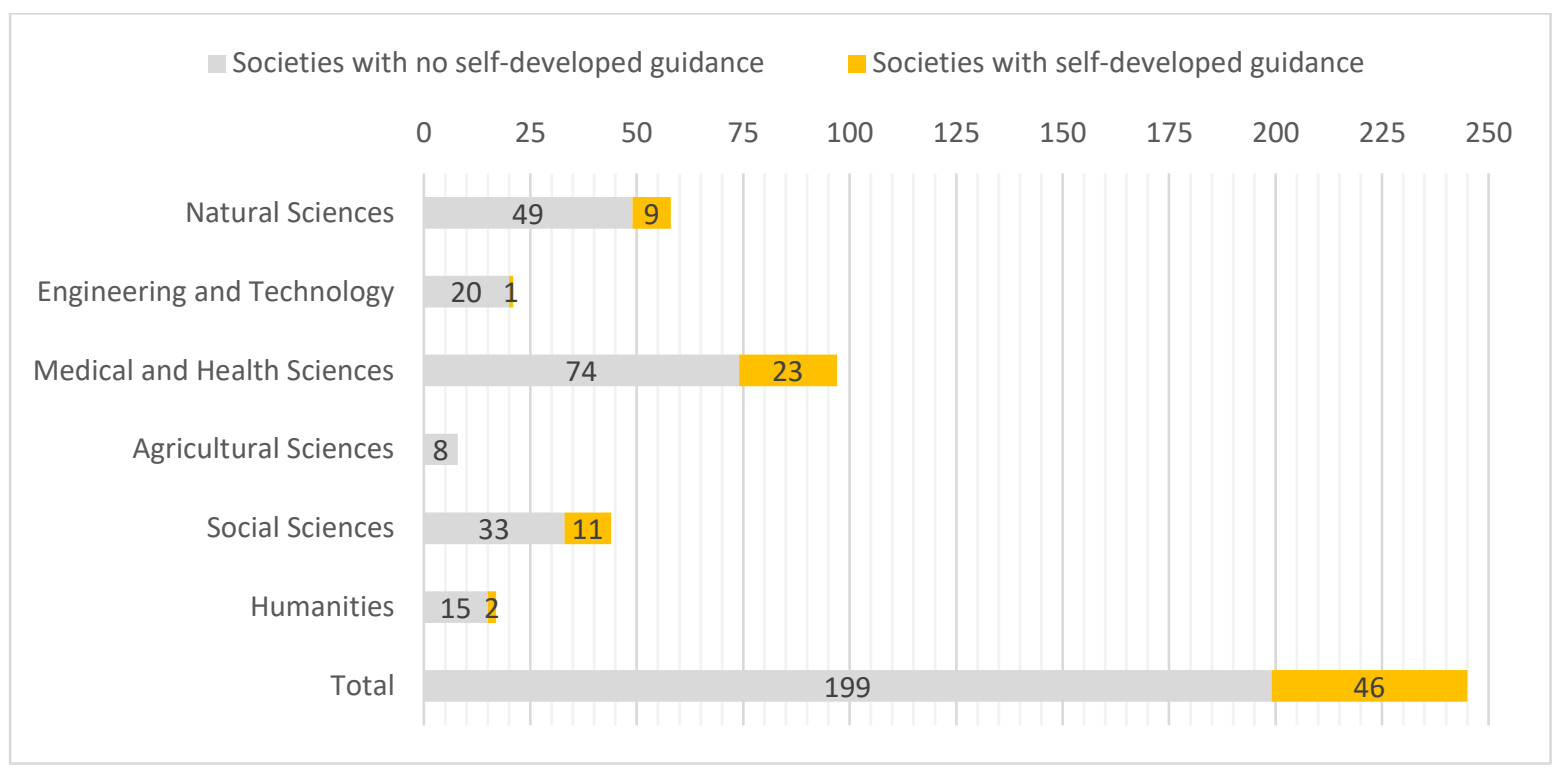

Figure 2: Distribution of self-developed guidance on RI across societies by discipline, and overall.

Among the societies that have developed their own guidance, we identified a total of 58 relevant documents $-28 \mathrm{CoCs}$ and 30 statements, guidelines or reports - reflecting guidance on research. Most societies have only one relevant document $(n=37)$, whereas six societies provide two documents each, and three societies provide three documents each.

\section{Principles}

The proportion of societies from each discipline that provide guidance related to specific principles of research is presented in Figure 3, with qualitative results discussed in section 1 and Table 2 (additional quantitative data is presented in Supplementary File 3, and additional illustrative quotes are presented in Supporting data file 4, available at: https://osf.io/9n8 $\mathrm{rm} /$ ). The data analysis file, which lists all sub-codes per main category of principles, can be found here: https://osf.io/y46b2/.

The ALLEA code begins with a description of four fundamental principles - reliability, honesty, respect and accountability - which should guide researchers in their work (15). Fifteen 
learned societies (Medical and Health Sciences: $n=9$, Natural Sciences: $n=3$, Humanities and Social Sciences: $n=3$ ) also outlined guiding principles in their documents. These principles are most frequently related to 'honesty' and 'respect', and least frequently to 'reliability' (Figure 3). 


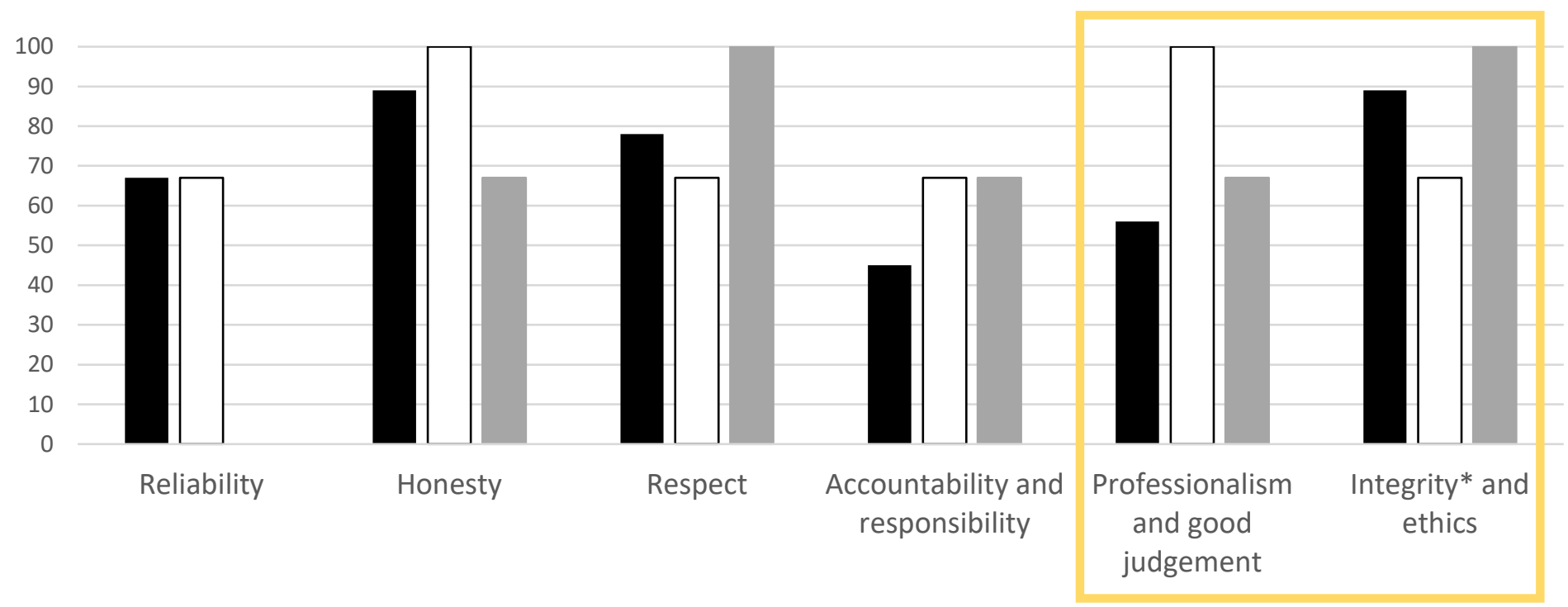

- Medical and Health Sciences

$\square$ Natural Sciences

Humanities and Social Sciences

Figure 3: Proportion (\%) of societies per discipline which explicitly refer to each main category of principles. Principles inside a yellow box were not mentioned in the ALLEA code, but were mentioned in societies guidance.

*Due to the methodological approach of analysing only those principle words explicitly mentioned in the "Principles" (or similar) sections of guidance documents, 'integrity' does not appear as an explicit principle in the ALLEA code (15). We do, however, recognise that integrity is a main over-arching principle of this document. 
The words used to describe guiding principles differed notably between disciplines (Table 2). Societies from the Medical and Health Sciences were the only ones to mention 'reliability' explicitly, although Natural Sciences societies referred to related terms. No 'reliability'-related principles were used by Humanities and Social Sciences societies. 'Honesty', as well as 'transparency', was mentioned by societies from all disciplines, and was the most frequently mentioned sub-category of principles within the Medical and Health Sciences. However, when referring to this principle Medical and Health Sciences and Natural Sciences societies seemed to emphasize different aspects, namely honesty in relation to personal interests and influences, compared with honesty in relation to scientific judgement and interpretation, respectively. 'Respect' was also mentioned by societies from all disciplines, but here Natural Sciences societies more frequently mentioned respect in the context of equality, diversity and inclusion (EDI), whereas Medical and Health Sciences and Humanities and Social Sciences societies more frequently used this, and related terms, in the context of the rights of research participants. 'Respect'-related principles were the most frequently mentioned sub-category for both the Natural Sciences and Humanities and Social Sciences. 'Accountability' was only mentioned by some Medical and Health Sciences societies, and across all disciplines 'responsibility' was the preferred term.

In addition to principles reflective of those mentioned in the ALLEA code, guiding principles related to 'professionalism and good judgement' and 'integrity and ethics' were also often outlined in societies' guidance. 'Professionalism and good judgement'-related principles were often mentioned, relative to other sub-categories of principles, by the Natural Sciences and Humanities and Social Sciences, but less so by Medical and Health Sciences societies. The use of terms related to this category of principles was similar in the Medical and Health Sciences and Humanities and Social Sciences societies, with particular attention on 'professionalism' and '(being) competent/qualified/(an) expert', as can be seen in the quote below from The Federation of European Pharmacological Societies (Medical and Health Sciences), whereas Natural Sciences societies referred to a range of related terms:

Professional integrity: pharmacologists should dedicate themselves to the highest standards of competence, honesty, professionalism and social and community responsibility.

There was an emphasis on 'integrity', rather than 'ethics', in the explicitly mentioned guiding principles of societies across disciplines. 
Table 2: Explicit guiding principles - Key points and differences between disciplines. The use of [] around a section of text indicates that this is an assessment of the content of the guidance documents, rather than a simple summary of the content itself.

\begin{tabular}{|c|c|c|c|}
\hline Principle & Medical and Health Sciences & Natural Sciences & Humanities and Social Sciences \\
\hline Reliability & $\begin{array}{l}\text { 'Reliability' itself mentioned, } \\
\text { alongside related terms }\end{array}$ & $\begin{array}{l}\text { Only related terms, such as } \\
\text { 'reproducibility' and 'rigor', are } \\
\text { used }\end{array}$ & Not mentioned \\
\hline Honesty & $\begin{array}{l}\text { Often discussed terms referring } \\
\text { predominantly to independence of } \\
\text { interests, such as 'transparency', } \\
\text { 'independence' and 'unbiasedness' } \\
\text { [This was the most used principle } \\
\text { for societies from this discipline] }\end{array}$ & $\begin{array}{l}\text { Often discussed in terms referring } \\
\text { predominantly to objectivity of } \\
\text { judgements, such as 'transparency', } \\
\text { 'objectivity' and 'truthfulness' }\end{array}$ & $\begin{array}{l}\text { 'Honesty' itself mentioned, } \\
\text { alongside 'transparency' }\end{array}$ \\
\hline Respect & $\begin{array}{l}\text { Often discussed in terms referring } \\
\text { predominantly to rights, such as } \\
\text { 'confidentiality/privacy' }\end{array}$ & $\begin{array}{l}\text { Often discussed in terms referring } \\
\text { predominantly to equality, diversity } \\
\text { and inclusion (EDI) } \\
\text { [This was the most used principle } \\
\text { for societies from this discipline] }\end{array}$ & $\begin{array}{l}\text { Often discussed in terms referring } \\
\text { predominantly to rights } \\
\text { [This was the most used principle } \\
\text { for societies from this discipline] }\end{array}$ \\
\hline Accountability and responsibility & $\begin{array}{l}\text { 'Accountability' itself mentioned by } \\
\text { some societies, but 'responsibility' is } \\
\text { more often mentioned }\end{array}$ & Only 'responsibility' is used & Only 'responsibility' is used \\
\hline Professionalism and good judgement & $\begin{array}{l}\text { Emphasis on 'professionalism' and } \\
\text { '(being) competent/qualified/(an) } \\
\text { expert' }\end{array}$ & $\begin{array}{l}\text { A range of terms, including } \\
\text { '(involvement in) } \\
\text { dialogue/debate/discourse', are used }\end{array}$ & $\begin{array}{l}\text { Emphasis on 'professionalism' and } \\
\text { '(being) competent/qualified/(an) } \\
\text { expert' }\end{array}$ \\
\hline
\end{tabular}




\section{Practices}

The proportion of societies that provide guidance related to specific research practices is presented in Figure 4, with qualitative results discussed in sections 2.1-2.5 and Tables 3-7 (additional quantitative data is presented in Supplementary File 4, and additional illustrative quotes are presented in Supporting data file 5, available at: https://osf.io/4pxh7/).

Both the ALLEA code and guidance from societies outline positive and negative research practices (15). For this analysis, practices were grouped into 5 categories: 'Research performance, publication, review and dissemination'; 'Safeguards'; 'Culture and processes of the research environment'; 'Collaborations, relationships and interactions'; and 'Misconduct, mistakes and unacceptable practices’ (Figure 4). 


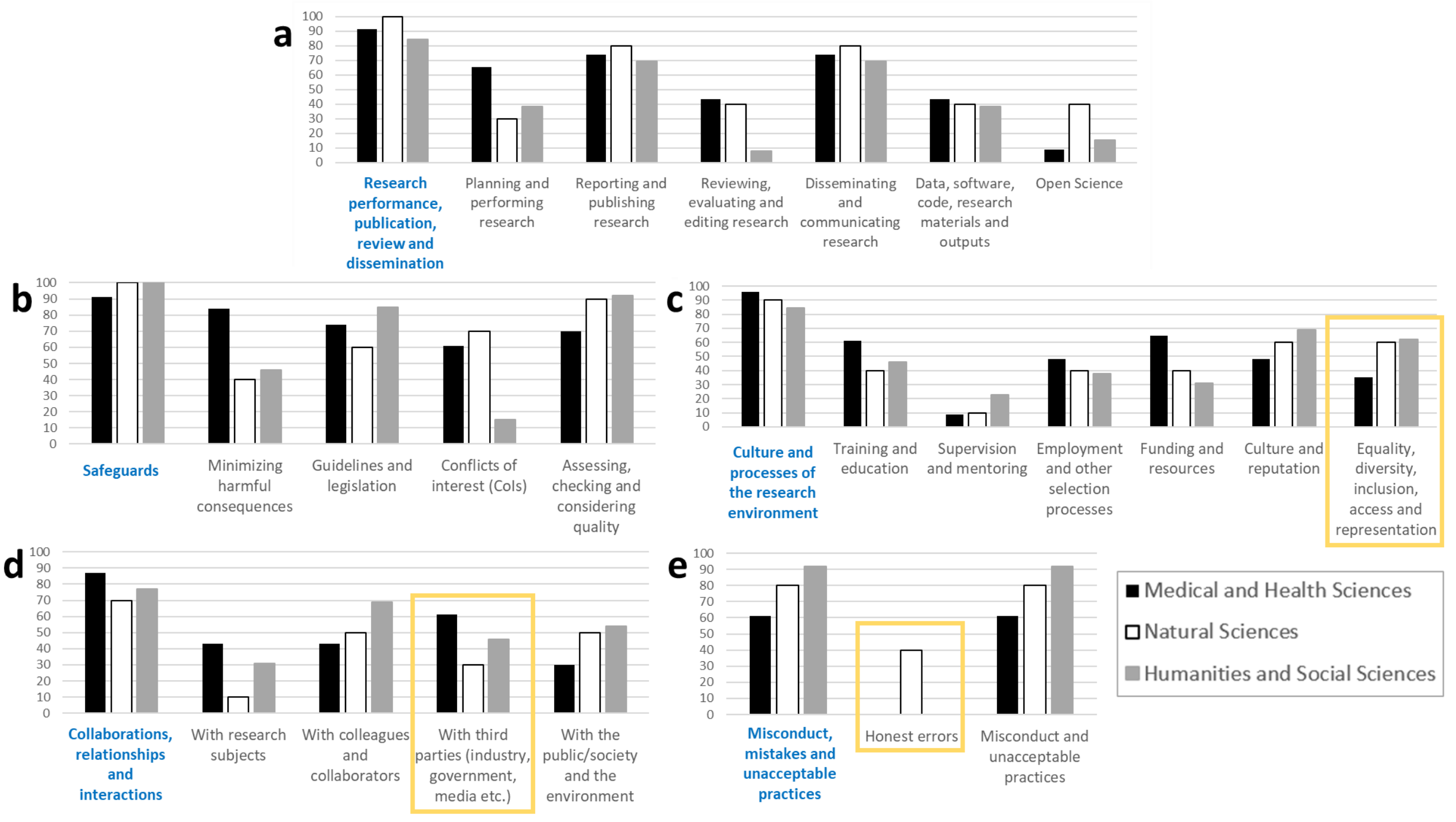

Figure 4: Proportion (\%) of societies per discipline which refer to each main (blue text) and sub-category of practices. Practices inside a yellow box were not mentioned in the ALLEA code, but were mentioned in societies guidance. 


\subsection{Research performance, publication, review and dissemination}

Recommendations in this category relate to distinct phases of research (e.g. 'planning and performing research') and specific practices that can be applicable across multiple phases of research (e.g. 'open science'). The ALLEA code states that research should be conducted in a careful and wellconsidered manner throughout all phases, and provides specific guidance on data use and stewardship (such as adherence to the FAIR principles) and open science (particularly open access publication) (15).

A general disciplinary difference in guidance on this category of practices is that Medical and Health Sciences societies place relatively more focus on the preparation and execution stages of research, whereas Natural Sciences societies provide more, and more detailed, guidance on interpreting, reporting and communicating about research (further details of this difference can be found in Table 3).

Responsible authorship, attribution, and acknowledgement practices are encouraged across disciplines, and several societies refer to additional guidance published by organizations such as the Committee on Publication Ethics (COPE), the International Committee of Medical Journal Editors (ICJME) (Medical and Health Sciences societies only), and the Open Access Scholarly Publishing Association (OASPA) (Natural Sciences societies only). Where recommendations about disseminating and communicating research are provided, these primarily concern society-organized conferences and events, which are seen as important opportunities for scholarly interaction and knowledge exchange, with many recommendations also encouraging the participation and representation of diverse audiences and panels. Societies from all disciplines emphasize the need for careful and considered communication, especially with the public and via traditional and social media.

Although recommendations from societies across all disciplines highlight the role of peer review in ensuring academic rigor and enhancing confidence in research quality, and highlight the importance of merit-based, fair, unbiased and well-justified decision-making, guidance on this phase of research is provided by less than half of societies across disciplines. Similarly, guidance on datarelated practices and open science, in particular, was provided by a minority of societies in all disciplines. As can be seen in the summary of key disciplinary priorities and differences in recommendations on research performance, publication, review and dissemination highlighted in Table 3, open science and data-related recommendations in particular vary substantially between disciplines.

Guidance from Medical and Health Sciences societies highlights regulatory and procedural aspects of research performance, particularly in relation to transparency regarding relations with industry and ethical considerations. For instance, the Federation of European Pharmacological Societies (Medical and Health Sciences) states that:

Research: it should be conducted to the highest standards possible, with moral integrity and respect for human dignity and animal welfare. This implies adherence to accepted guidelines of ethical practice, the relevant European regulations and national recommendations, and the appropriate scientific and ethical study approval.

Natural Sciences societies particularly highlight the importance of nuanced communication in relation to complex or controversial issues, such as climate change and nuclear research. For instance, the European Meteorological Society (Natural Sciences) states that:

[F]reedom of speech is fragile in the sense that [a lack of training in communication and ethics] can lead to the dissemination of incorrect or misleading information. High standards in science-related communication and media exposure, openness to rational debate and criticism, and honesty will 
increase the public confidence in science, relevant academies and scientists, in addition to benefitting society itself.

Alternatively, the emphasis in the Humanities and Social Sciences is placed on the professional, ethical and, especially, competent behavior of researchers. Guidance within this category of practices shows the heterogenous nature of this discipline, with specific considerations being raised dependent on the nature of the sub-discipline concerned (see Table 3). 
Table 3: Practices related to research performance, publication, review and dissemination - Key points and differences between disciplines. The use of [] around a section of text indicates that this is an assessment of the content of the guidance documents, rather than a simple summary of the content itself.

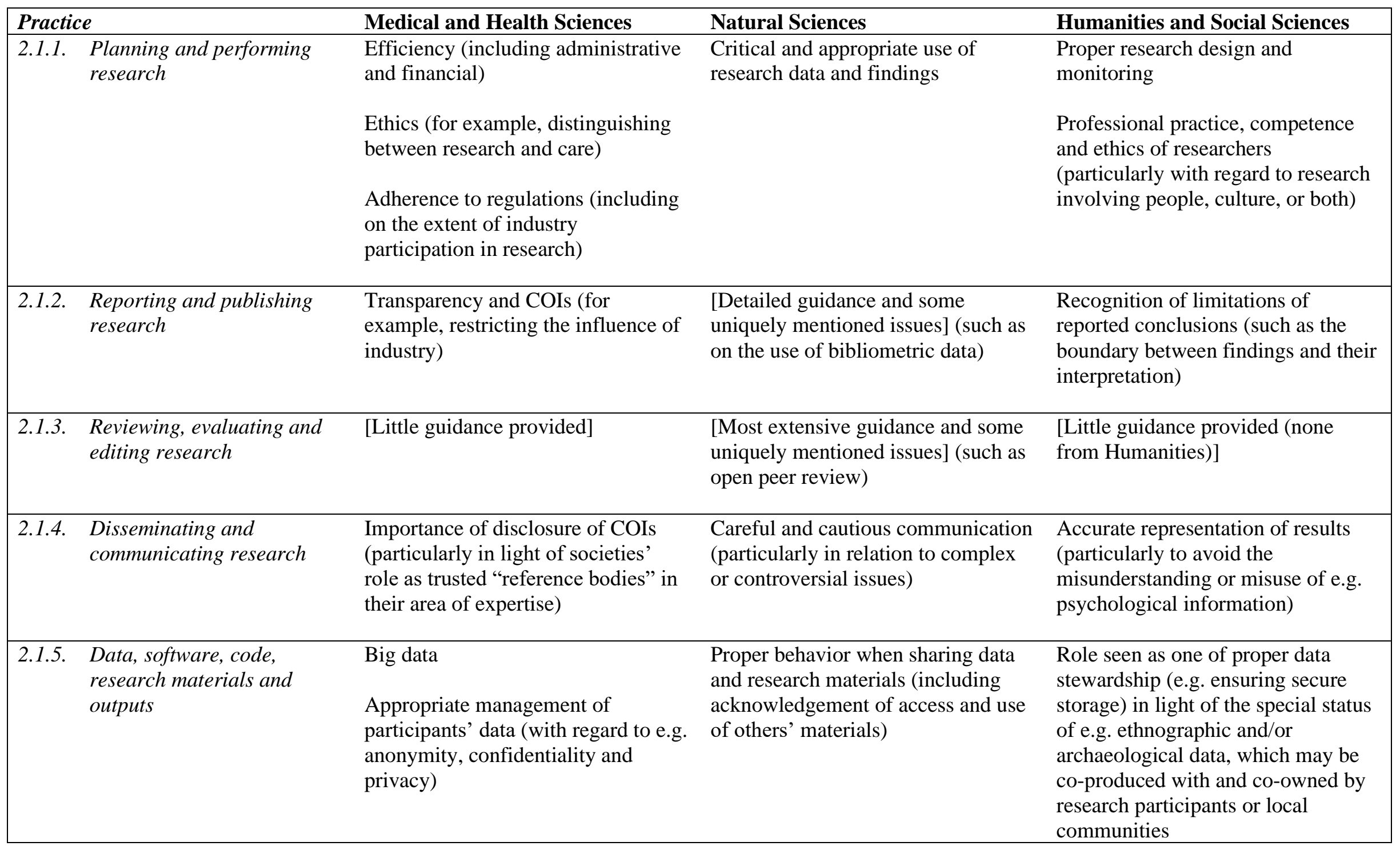




\begin{tabular}{|c|c|c|c|}
\hline 2.1.6. Open Science & $\begin{array}{l}\text { [Little guidance provided] - open } \\
\text { access publication sometimes } \\
\text { encouraged but emphasis is on open } \\
\text { science in relation to data-related } \\
\text { practices (such as adhering to the } \\
\text { FAIR principles (26)) }\end{array}$ & $\begin{array}{l}\text { [Broad range of recommendations } \\
\text { provided], covering open access to } \\
\text { both publications and research } \\
\text { materials (also citing the FAIR } \\
\text { principles (26)), open review, and } \\
\text { wider considerations relating to the } \\
\text { transition to open access }\end{array}$ & $\begin{array}{l}\text { [Little guidance provided (none } \\
\text { from Social Sciences)] - } \\
\text { encouragement of open access, but } \\
\text { difficulties in determining general } \\
\text { rules governing co-constructed or } \\
\text { co-owned data and materials noted }\end{array}$ \\
\hline
\end{tabular}




\subsection{Safeguards}

Safeguards refer to legal regulations, guidance and best practices for the prevention of undesirable research processes and outcomes, primarily those which cause harm to research subjects (human and animal), cultural heritage and the environment, but including threats to RI and research quality. The ALLEA code states that researchers should comply with relevant codes and regulations, respect research subjects, protect the welfare of the community and those involved in research, and manage research-related harms and risks (15).

Societies from all disciplines make recommendations to prevent negative consequences of violations of RI. Recommendations on the role of official guidance (both legally binding and advisory) covers both references to existing guidelines, including the ALLEA code (referred to by the European Association of Social Psychology), and recommendations to researchers to make themselves aware of relevant, but unnamed, legal and ethical provisions (existing guidelines referred to by societies can be found in Supporting data file 3, available at: https://osf.io/x925z/). Societies from all disciplines mention attaining and maintaining quality, high standards or best practice as desirable, but guidance from Medical and Health Sciences societies shows most focus on this, particularly in relation to the reliability of research (further details of this difference can be found in Table 4).

As can be seen in the summary of key disciplinary priorities and differences in recommendations on safeguards highlighted in Table 4, Medical and Health Sciences societies provide the most thorough and specific recommendations on disclosing and handling conflicts of interest (COIs). They often present reasons and explanations for adhering to COI-related policies to justify their importance, such as maintaining trust in medical research and practice, and the potential pitfalls or hazards of industry support for research is a common theme. For instance, the Federation of European Nutrition Societies (Medical and Health Sciences) states:

Conflicts of interest can lead to harmful misperceptions of scientists and the scientific enterprise.

When large sums of money are involved, it may be difficult for the public, legislators, the judicial system, and even colleagues to be convinced that results were not biased for personal gain. Perceived impropriety can result in consequences as damaging as if intentional misconduct had been committed. 
Table 4: Practices related to safeguards - Key points and differences between disciplines. The use of [] around a section of text indicates that this is an assessment of the content of the guidance documents, rather than a simple summary of the content itself.

\begin{tabular}{|c|c|c|c|c|}
\hline \multicolumn{2}{|c|}{ Practice } & \multirow[b]{2}{*}{$\begin{array}{l}\text { Medical and Health Sciences } \\
\text { Risk assessment and management, } \\
\text { particularly with regard to } \\
\text { participants' rights and welfare (and } \\
\text { balancing this with reducing } \\
\text { bureaucratic and administrative } \\
\text { burdens) }\end{array}$} & & \\
\hline 2.2 .1 & $\begin{array}{l}\text { Minimizing harmful } \\
\text { consequences }\end{array}$ & & $\begin{array}{l}\text { Acknowledgement of the inherent } \\
\text { uncertainty or potential for misuse of } \\
\text { data, information and knowledge } \\
\text { generated within this discipline }\end{array}$ & $\begin{array}{l}\text { Maintenance of awareness of the } \\
\text { limits of researchers' competence } \\
\text { Avoidance of research with the } \\
\text { potential to erode public trust } \\
\text { (particularly due to reliance on the } \\
\text { cooperation of the public as } \\
\text { participants in research) }\end{array}$ \\
\hline 2.2 .2 & Guidelines and legislation & $\begin{array}{l}\text { Privacy and data protection } \\
\text { regulations (such as the GDPR (27)) } \\
\text { Ethical practice regulations (such as } \\
\text { the Declaration of Helsinki (28)) } \\
\text { Anti-bribery and corruption } \\
\text { legislation }\end{array}$ & $\begin{array}{l}\text { Conduct at conferences and events } \\
\text { (such as guidelines for presenters or } \\
\text { misconduct policies) }\end{array}$ & $\begin{array}{l}\text { Privacy and data protection } \\
\text { regulations } \\
\text { Ethical practice regulations } \\
\text { Intellectual property } \\
\text { Guidance on fieldwork and } \\
\text { professional standards }\end{array}$ \\
\hline 2.2 .3 & Conflicts of interest (COI) & $\begin{array}{l}\text { What constitutes a COI, specific } \\
\text { procedures to ensure their proper } \\
\text { disclosure and handling, how COIs } \\
\text { could affect research and research- } \\
\text { related processes (such as hiring and } \\
\text { nomination), sanctions in the case of } \\
\text { non-adherence to stipulated } \\
\text { procedures }\end{array}$ & $\begin{array}{l}\text { [Guidance provided primarily in the } \\
\text { context of] publication-related } \\
\text { activities and decisions }\end{array}$ & $\begin{array}{l}\text { [Little guidance provided] - } \\
\text { emphasizes the need to avoid } \\
\text { conflicts that may arise from having } \\
\text { a dual role or a relationship with an } \\
\text { imbalance of power between parties }\end{array}$ \\
\hline 2.2 .4 & $\begin{array}{l}\text { Assessing, checking and } \\
\text { considering quality }\end{array}$ & $\begin{array}{l}\text { Quality indicators include reliability, } \\
\text { usefulness and usability, innovation, } \\
\text { timeliness and soundness }\end{array}$ & $\begin{array}{l}\text { Quality indicators include usefulness } \\
\text { and usability, soundness and clarity }\end{array}$ & Primary quality indicator is clarity \\
\hline
\end{tabular}




\subsection{Culture and processes of the research environment}

This category reflects practices that are indirectly related to research in that they influence research performance but are not part of it as such. Recommendations in the ALLEA code related to the 'Research Environment' and 'Training, Supervision and Mentoring', as well as education, culture and reputation, and selection processes for e.g. employment or the allocation of funding are included within this category (15).

Guidance on the culture and reputation of the society, discipline, or both is provided by societies across disciplines. As can be seen in the summary of key disciplinary priorities and differences in recommendations on culture and processes of the research environment highlighted in Table 5, this often reflects disciplinary considerations. This is exemplified in the below quote from the European Academy of Allergy and Clinical Immunology (Medical and Health Sciences), which describes cultural and reputational considerations:

In order to be effective, EAACI needs to be viewed by the Allergists \& Immunologists, the scientific community, the various social bodies, the general public, industry, media and political decision makers, as a scientific society of special competence, high respect and integrity.

Societies from all disciplines recognize the need for fair and transparent selection procedures in order to ensure equal opportunities and increase the participation and representation of marginalized groups. This sub-category, along with training and education and funding and resources, is seen as being susceptible to influence from industry, and receives most attention in guidance from Medical and Health Sciences societies (further details of this difference can be found in Table 3). In contrast, guidance on supervision and mentoring is provided by less than one quarter of societies in any discipline.

In addition to practices recommended in the ALLEA code, roughly half of all societies provide guidance on practices categorized as relating to 'equality, diversity, inclusion, access and representation'. Societies from all disciplines condemn discrimination and harassment, and recognize the benefits for both the quality of research and the research culture of increasing the representation and participation of marginalized groups, and equality, diversity and inclusion (EDI) more generally. An example, from the European Astronomical Society (Natural Sciences), is shown below:

The European Astronomical Society (EAS) recognizes that diversity among astronomers brings diversity of ideas, methods and sensitivity, which is beneficial to astronomy. In addition, it is critical for the future of astronomy, and science in general, that young people can see evidence that scientists can succeed regardless of, e.g., gender, nationality, ethnic origin, or social origin.

Eight societies also provide specific policy statements or reports on EDI, whilst two provide guidelines for conferences which name harassment and discrimination as serious forms of professional misconduct, and recommend that conference organizers improve access, inclusion, participation and representation of, for example, young researchers, female researchers, researchers with children, and researchers from or working in low- and middle-income countries. Societies across disciplines often link specific EDI-related initiatives and goals to other issues, such as 'disseminating and communicating research', 'employment and other selection processes', allocation of 'funding and resources', and 'training and education'. 
Table 5: Practices related to culture and processes of the research environment - Key points and differences between disciplines. The use of [] around a section of text indicates that this is an assessment of the content of the guidance documents, rather than a simple summary of the content itself.

\begin{tabular}{|c|c|c|c|c|}
\hline \multicolumn{2}{|c|}{ Practice } & Medical and Health Sciences & Natural Sciences & Humanities and Social Sciences \\
\hline 2.3 .1 & Training and education & $\begin{array}{l}\text { [Most extensive guidance], covering } \\
\text { the regulation of Continuing } \\
\text { Medical Education (CME) and } \\
\text { Continuing Professional } \\
\text { Development (CPD) } \\
\text { Attention to the effects of influence, } \\
\text { both positive and negative, of } \\
\text { industry financing on the priorities, } \\
\text { quality and accessibility of } \\
\text { educational materials and activities }\end{array}$ & $\begin{array}{l}\text { Need for adequate training and } \\
\text { education with equitable } \\
\text { opportunities for access }\end{array}$ & $\begin{array}{l}\text { Emphasize developing the } \\
\text { competence of trainers, in addition } \\
\text { to trainees } \\
\text { Ethical awareness as focus for } \\
\text { training and education }\end{array}$ \\
\hline 2.3 .2 & Supervision and mentoring & $\begin{array}{l}\text { [Little guidance provided] - } \\
\text { extended responsibility of supervisor } \\
\text { for the actions of supervisees } \\
\text { (particularly in relation to welfare of } \\
\text { research participants) }\end{array}$ & $\begin{array}{l}\text { [Little guidance provided] - } \\
\text { importance of providing good } \\
\text { quality mentoring and supervision in } \\
\text { an inclusive, respectful and unbiased } \\
\text { manner }\end{array}$ & $\begin{array}{l}\text { [Little guidance provided] - covers } \\
\text { topics mentioned by Medical and } \\
\text { Health and Natural Sciences }\end{array}$ \\
\hline 2.3 .3 & $\begin{array}{l}\text { Employment and other } \\
\text { selection processes }\end{array}$ & Avoidance and declaration of COIs & $\begin{array}{l}\text { Establishment of clear, consistent } \\
\text { and fair hiring procedures }\end{array}$ & $\begin{array}{l}\text { Duty of care and standards that } \\
\text { apply to employers of early career } \\
\text { researchers and those undertaking } \\
\text { fieldwork }\end{array}$ \\
\hline 2.3 .4 & Funding and resources & $\begin{array}{l}\text { Need to reduce or cover the costs of } \\
\text { research whilst avoiding undue } \\
\text { influence from industry sponsors } \\
\text { Regulations governing financial } \\
\text { COIs } \\
\text { Rules under which sponsorship, and } \\
\text { what kind, can be accepted, and }\end{array}$ & $\begin{array}{l}\text { Need to disclose sources of financial } \\
\text { support } \\
\text { Need to ensure publicly funded } \\
\text { research is made freely available and } \\
\text { not used to extract excessive private } \\
\text { profits }\end{array}$ & $\begin{array}{l}\text { Encourage fair and inclusive } \\
\text { processes for allocation }\end{array}$ \\
\hline
\end{tabular}




\begin{tabular}{|c|c|c|c|c|}
\hline & & \multicolumn{3}{|l|}{$\begin{array}{l}\text { suggested limits to the influence of } \\
\text { sponsors }\end{array}$} \\
\hline 2.3 .5 & Culture and reputation & $\begin{array}{l}\text { Encourage culture of responsibility } \\
\text { and avoidance of behavior that could } \\
\text { cause reputational damage, } \\
\text { particularly regarding the } \\
\text { trustworthiness and integrity of the } \\
\text { discipline or the profession in the } \\
\text { eyes of the public }\end{array}$ & $\begin{array}{l}\text { Emphasize the importance of an } \\
\text { inclusive, collaborative community } \\
\text { where individuals are free to engage } \\
\text { in open dialogue } \\
\text { Recognize the role of the society in } \\
\text { providing responsible leadership to } \\
\text { foster positive environments }\end{array}$ & $\begin{array}{l}\text { Emphasize the role of the researcher } \\
\text { as a representative of the discipline } \\
\text { and profession, therefore the } \\
\text { importance of maintaining high } \\
\text { standards of professional and ethical } \\
\text { conduct } \\
\text { Encourage fostering an inclusive and } \\
\text { welcoming environment }\end{array}$ \\
\hline 2.3 .6 & $\begin{array}{l}\text { Equality, diversity, } \\
\text { inclusion, access and } \\
\text { representation }\end{array}$ & $\begin{array}{l}\text { Focus on addressing gender } \\
\text { imbalance in science }\end{array}$ & $\begin{array}{l}\text { [Most extensive and detailed } \\
\text { guidance], covering the need to } \\
\text { ensure that the diversity of the } \\
\text { community is reflected at all levels } \\
\text { and in all activities, and the } \\
\text { importance of addressing } \\
\text { unconscious biases }\end{array}$ & $\begin{array}{l}\text { Recognition of the need, and some } \\
\text { specific recommendations provided, } \\
\text { to not only combat discrimination } \\
\text { but promote diversity (e.g. at } \\
\text { conferences and events) }\end{array}$ \\
\hline
\end{tabular}




\subsection{Collaborations, relationships and interactions}

This category concerns interactions with research participants, colleagues, third parties (such as industry, the media and government), and the public or society in general. The ALLEA code states that collaborative working involves striving for consensus and shared responsibility, joint decisionmaking, information sharing and consultation amongst all parties involved in research (15).

Guidance from all disciplines asserts that interactions should be cooperative and respectful, and that collaborations and relationships are beneficial to learned societies, the discipline and the academic field as a whole. The differential emphasis on certain types of relationships seen in societies guidance reflects the considerations of each discipline, as can be seen in the summary of key disciplinary priorities and differences in recommendations on collaborations, relationships and interactions highlighted in Table 6 . For example, $50 \%$ of recommendations in this category from Medical and Health Sciences societies refer to relationships with third parties, compared with $16 \%$ and $17 \%$ in the Natural Sciences and Humanities and Social Sciences, respectively. Similarly, 14\% and 19\% of recommendations from Medical and Health Sciences and Humanities and Social Sciences societies, respectively, refer to relationships with research subjects, compared with $3 \%$ in the Natural Sciences.

Considering the effects of research activities on society at large is important across disciplines. This is particularly true for some Humanities and Social Sciences societies who see their subject matter as, at a minimum, relying on, or potentially being co-created with (sometimes vulnerable) participants and communities. The quote below from the European Association of Social Anthropologists (Humanities and Social Sciences) describes an instance of this:

Archiving: In ethnographic research "data" are always part of a social relationship. It is not easily reducible to a fixed and finished product. As such, it may not always be possible to archive or store research materials. In other cases, the archiving of ethnographic materials will require specific technical features (e.g. different roles for access, editing, sharing or privacy) not available in most institutional repositories. 
Table 6: Practices related to collaborations, relationships and interactions - Key points and differences between disciplines. The use of [] around a section of text indicates that this is an assessment of the content of the guidance documents, rather than a simple summary of the content itself.

\begin{tabular}{|c|c|c|c|c|}
\hline \multicolumn{2}{|c|}{ Practice } & Medical and Health Sciences & Natural Sciences & Humanities and Social Sciences \\
\hline 2.4 .1 & With research subjects & $\begin{array}{l}\text { The rights, welfare and dignity of } \\
\text { research participants and partners, } \\
\text { and animals, are considered } \\
\text { paramount }\end{array}$ & [Little guidance provided] & $\begin{array}{l}\text { Duty of care for research } \\
\text { participants }\end{array}$ \\
\hline & & $\begin{array}{l}\text { Taking a "patient-centered" } \\
\text { approach to research is encouraged } \\
\text { by some }\end{array}$ & & \\
\hline 2.4 .2 & $\begin{array}{l}\text { With colleagues and } \\
\text { collaborators }\end{array}$ & $\begin{array}{l}\text { Focus on fostering meaningful } \\
\text { productive partnerships }\end{array}$ & $\begin{array}{l}\text { Collegial and supportive } \\
\text { relationships with colleagues } \\
\text { encouraged }\end{array}$ & $\begin{array}{l}\text { Positive engagement with } \\
\text { colleagues, particularly in the form } \\
\text { of open and constructive dialogue, is } \\
\text { encouraged }\end{array}$ \\
\hline 2.4 .3 & $\begin{array}{l}\text { With third parties (industry, } \\
\text { government, media etc.) }\end{array}$ & $\begin{array}{l}\text { Necessity and importance of } \\
\text { collaborations with industry for the } \\
\text { advancement of clinical research, as } \\
\text { well as the need to carefully regulate } \\
\text { these collaborations, discussed } \\
\text { extensively }\end{array}$ & $\begin{array}{l}\text { [Little guidance provided] - often } \\
\text { discussed in the context of engaging } \\
\text { with political concerns }\end{array}$ & $\begin{array}{l}\text { Avoidance of problematic } \\
\text { communication with the media } \\
\text { advised }\end{array}$ \\
\hline 2.4 .4 & $\begin{array}{l}\text { With the public/society and } \\
\text { the environment }\end{array}$ & $\begin{array}{l}\text { Gaining and maintaining public } \\
\text { confidence } \\
\text { Delivering health and knowledge as } \\
\text { public goods }\end{array}$ & $\begin{array}{l}\text { Engagement encouraged primarily } \\
\text { via provision of understandable and } \\
\text { unambiguous information, as well as } \\
\text { listening and responding to societal } \\
\text { concerns }\end{array}$ & $\begin{array}{l}\text { Focus on nuances of conducting } \\
\text { research with (potentially } \\
\text { vulnerable) communities and groups } \\
\text { Calls for special efforts to overcome } \\
\text { difficulties with storing, protecting } \\
\text { and sharing materials and findings }\end{array}$ \\
\hline
\end{tabular}




\subsection{Misconduct, mistakes and unacceptable practices}

This category covers the prevention and handling of practices that threaten research integrity. The ALLEA code defines violations of RI as including research misconduct (falsification, fabrication, plagiarism) and some questionable and unacceptable practices, such as withholding research results, misrepresenting research achievements and manipulating authorship. The ALLEA code also provides guidance on dealing with violations of RI (15).

Societies across disciplines outline what they consider to be the most problematic forms of misconduct, and outline sanctions that may apply in proven cases. These often amount to exclusion from the activity in question (e.g. a conference) and potentially revocation of society membership. Medical and Health Sciences societies particularly emphasize financial impropriety as a serious form of misconduct, with six societies within this discipline providing stand-alone documents on procedures for handling competing interests. Natural Sciences societies most commonly address misconduct and unacceptable practices relating to authorship, attribution and/or acknowledgement, as well as highlighting the seriousness of harassment, discrimination and abuse, where a zero-tolerance approach is encouraged. Additional details can be seen in the summary of key disciplinary priorities and differences in recommendations on misconduct, mistakes and unacceptable practices highlighted in Table 6.

In contrast with the ALLEA code, and societies from other disciplines, four Natural Sciences societies make a distinction between misconduct and unacceptable practices on one hand, and honest mistakes on the other. These societies describe the nature of this difference, often along with how honest errors should be handled. An example delineating honest errors from misconduct and unacceptable practices, from the European Geosciences Union (Natural Sciences), is shown below:

Misconduct is defined as a violation - proven by evidence - of the standard codes of scholarly conduct and ethical behavior in scientific research. Misconduct also includes the unethical and/or biased treatment of people in a professional setting and while participating in scientific activities. Misconduct includes actions such as discrimination, harassment, bullying, coercion, intimidation, censorship and plagiarism. Misconduct does not include errors of judgment; honest errors in the recording, selection, or analysis of data; or differences in opinions involving the interpretation of data and results. 
Table 7: Practices related to misconduct, mistakes and unacceptable practices - Key points and differences between disciplines. The use of [] around a section of text indicates that this is an assessment of the content of the guidance documents, rather than a simple summary of the content itself.

\begin{tabular}{|c|c|c|c|}
\hline Practice & Medical and Health Sciences & Natural Sciences & Humanities and Social Sciences \\
\hline $\begin{array}{ll}2.5 .1 & \text { Misconduct and } \\
& \text { unacceptable practices }\end{array}$ & $\begin{array}{l}\text { Financial impropriety (e.g. the } \\
\text { exertion of undue influence or } \\
\text { failure to declare COIs) seen as a } \\
\text { serious form of misconduct }\end{array}$ & $\begin{array}{l}\text { Poor authorship, attribution and/or } \\
\text { acknowledgement (e.g. plagiarism } \\
\text { and citation manipulation) practices, } \\
\text { as well as harassment, } \\
\text { discrimination and abuse, seen as } \\
\text { serious forms of misconduct }\end{array}$ & $\begin{array}{l}\text { Focus on harassment and } \\
\text { discrimination, including the } \\
\text { mistreatment of junior colleagues, } \\
\text { and misuse of discipline-specific } \\
\text { knowledge and/or power (e.g. } \\
\text { psychological) }\end{array}$ \\
\hline 2.5.2 Dealing with honest errors & [No guidance provided] & $\begin{array}{l}\text { [Little guidance provided] - } \\
\text { distinction made between this and } \\
\text { misconduct and unacceptable } \\
\text { practices }\end{array}$ & [No guidance provided] \\
\hline
\end{tabular}




\section{Responsible parties}

In addition to recommending specific practices, learned societies frequently identify which party should be responsible for these practices. In general, from all disciplines, research institutions, including societies, are most often considered to be responsible for implementing recommendations, closely followed by individual researchers, including society members. The roles and responsibilities of these parties seem to be conceived of similarly across disciplines.

The ALLEA code states that research institutions should demonstrate leadership in providing policies on good research practice and the handling of violations of RI, and should ensure a prevailing culture of RI (15). The primary responsibility of research institutions and societies, as described in societies' guidance, is to develop and disseminate guidelines, rules and regulations for appropriate conduct, particularly in relation to practices related to culture and the research environment, safeguards, and handling misconduct. The role of societies, specifically, is to protect the interests of their members and support researchers, and to advance knowledge and practice.

Whilst the ALLEA code goes on to stipulate quite specific recommendations for directly facilitating and carrying out research for both research institutions and researchers themselves, recommendations from societies tend to refer to more general conduct and comportment. Research organizations and societies are often seen to play a supportive, rather than guiding, role (although exceptions exist, such as the European Nuclear Society, who see responsible leadership as a core value). For example, some societies see practices categorized as relating to 'encouraging and promoting research' as one of their responsibilities, an activity not covered by the ALLEA code. Societies across disciplines describe this activity as important for the advancement of science and knowledge, with Medical and Health Sciences societies describing it as being important for medical advancement and the promotion of health, in addition.

The majority of recommendations in the ALLEA code focus on individuals as the main responsible party, with engaging in ethics and RI training, working conscientiously and complying with relevant codes and regulations being some of their responsibilities (15). The primary responsibility of individual researchers and society members, as described in societies' guidance, is to adhere to the high academic and professional standards set out by societies and to behave ethically and competently. Individual researchers and society members are also advised to be welcoming and inclusive in their day-to-day conduct and to actively pursue and engage in training and education.

\section{DISCUSSION}

In this study, we assessed the frequency and distribution of guidance on RI from societies across disciplines. We compared this guidance with the ALLEA code to determine whether guidance from specific disciplines is consistent with the more general guidance provided in the ALLEA code, and if there are discipline-specific considerations represented in societies' guidance which are not currently covered by the ALLEA code. Finally, we highlighted the similarities and differences between societies' guidance to assess how RI is conceptualised and operationalised across disciplines.

Firstly, a vast majority of societies provide no guidance on RI for their members. This is especially pronounced in the Agricultural Sciences and Engineering and Technology, but also the Humanities and Natural Sciences. Despite many societies across disciplines referring to a wide range of other disciplinary and cross-disciplinary guidelines and legislation, the ALLEA code was referred to only twice. The lack of guidance from many societies might suggest an awareness of and adherence to the abundance of adequate RI guidelines present elsewhere; however, only eight societies (3.3\%) 
explicitly promote adherence to existing RI guidelines rather than providing their own guidance on RI. In addition, given that existing RI guidelines developed by other organisations (not societies) are dominated by initiatives within the Medical and Health and Social Sciences $(29,30)$, this explanation does not sufficiently account for the greater proportion of guidance documents provided by societies from these disciplines within our sample. Medical and Health Sciences societies, which we found provided the greatest number of guidance documents, likely do so for several reasons, such as the involvement of human subjects in research, and therefore the greater legal repercussions of misconduct, as well as the historical development of professional CoCs within this discipline (31). The relative lack of guidance from societies within other disciplines is particularly striking considering the role of societies within the research landscape and their related responsibilities, which includes providing guidance on correct behaviour as one way of supporting researchers in their professional role (32-34). Such guidance, especially from disciplines which are currently particularly under-represented in RI initiatives, would be valuable in providing context-sensitive recommendations for researchers on how to conduct research responsibly.

Secondly, of those societies that provide recommendations for their members, most show a slightly different focus on RI than the ALLEA code. Whilst the ALLEA code primarily outlines concrete actions and specific practices that researchers should perform, societies' guidance tends to emphasise the professional competencies, skills and ethical concerns of their disciplines, often with a great deal of attention to social and societal dimensions of research, including how to create a collegial and inclusive research community and the importance of proper public engagement to maintain public trust in research. This finding may reflect the role of societies as membership organisations that are only indirectly involved in research, via supporting researchers, rather than being directly involved themselves (32-34). This view is also supported by the relative underrepresentation in societies' guidance of recommendations on some practices - such as supervision and mentoring, open science and data-related practices - that typically occur in the context of research institutions, either as a condition of employment as a researcher or because they often are dependent on institutional funding and infrastructures. In addition, societies' recommendations refer explicitly to 'respect'-related principles (including 'equality', 'diversity' and 'inclusion' specifically, as well as related terms, which are not mentioned as fundamental principles in the ALLEA code) more frequently than research-specific fundamental principles, such as 'reliability', or principles which suggest direct liability for research, such as 'accountability'. On one hand, it would be valuable for more societies to translate cross-disciplinary RI guidance on conducting research to suit their specific priorities and concerns, but, on the other hand, there is increasing acknowledgement that research behaviour is largely influenced by the environment in which researchers operate $(6,35-39)$, implying that considering and focusing on the social aspects of research is crucial to fostering research quality and integrity, albeit indirectly. In fact, several societies' guidance documents make an explicit link between a research culture that encourages and facilitates the participation of traditionally marginalised groups with improving research quality. On this point, societies' recommendations differ from other research-related guidance documents, such as the Hong Kong principles, which, similarly to the ALLEA code, do not address this type of social issue explicitly (40-42). It has been suggested that a reason for this is that EDI is a human resource management issue, rather than an RI issue (40), however, our analysis suggests that this topic cuts across domains, often being mentioned in reference to all other 'culture and processes of the research environment' sub-categories (including e.g. employment), in addition to being seen as a way to improve research quality (43). Taken together, these considerations suggest that while societies' guidance and the ALLEA code are not perfect reflections of one another, guidance from societies can be complementary in that it addresses important aspects of research not covered in detail by the ALLEA code.

Thirdly, the differences found in guidance from societies of different disciplines seem to reflect differences in epistemologies and the practicalities of how research is conducted between disciplines (44). At the risk of oversimplifying, Medical and Health Sciences societies' guidance 
focuses on regulatory and procedural aspects of research established to protect research participants, as seen for example in recommendations to ensure the secure handling of research data and to discourage and manage COIs. The extensive attention paid to COIs, and interactions with industry more generally in the Medical and Health Sciences, may also indicate attempts to safeguard against issues which have negatively affected RI within this discipline in the past (45). Natural Sciences societies ask researchers to consider the wider impacts of their work, and highlight the need to balance caution with openness when judging the quality of data and conclusions and communicating these with the public, especially in the case of complex and/or controversial research findings. To this end, Natural Sciences societies provide a greater depth and breadth of guidance regarding reporting and disseminating research. Furthermore, they are the only discipline to distinguish between honest errors (e.g., in interpreting data) and intentional misconduct or unacceptable practices (a distinction that is also missing from the ALLEA code) $(46,47)$. Humanities and Social Sciences societies' guidance often focuses on the competencies of researchers, especially in navigating ethical considerations and responsibilities, such as the problems posed to typical notions of e.g. data ownership by the unique nature of research materials, data and findings within this discipline. The higher prevalence of guidance from specific sub-disciplines within the Humanities and Social Sciences highlights the heterogenous nature of these disciplines, which includes more applied sub-disciplines often involving fieldwork and research participants or partners, such as archaeology, anthropology and psychology. This is reflected in the fact that there is often overlap between recommendations provided by Medical and Health Sciences societies and Humanities and Social Sciences societies on topics such as 'Safeguards' and 'Collaborations, relationships and interactions', and would imply that recommendations from "traditional" or "typical" Humanities and Social Sciences disciplines (i.e. those that are more distinct from the Medical and Health or Natural Sciences) are particularly limited.

Research practices recommended in relation to data and open science are particularly different between disciplines. There remains a need to better understand the appropriateness and impact of open science practices, including those related to data management, across disciplines in light of discipline-specific concerns. Open science policies and practices have developed primarily to support the needs of some Social Sciences (specifically psychology) and Science, Technology, Engineering and Math (STEM) disciplines (48), and have spread throughout the Medical and Health Sciences. Researchers subscribing to more interpretivist and constructivist research paradigms, or using non-empirical research methods, may support the idea of open science methodologies but require specific adaptations, or may consider open science practices (or the ways these are typically implemented), such as open methods to support reproducibility, as less relevant or even detrimental to or conflicting with their daily practices, as explicitly mentioned in guidance from the European Association of Social Anthropologists. Indeed, the term open "science" (rather than "research" or "scholarship") inadvertently excludes the Humanities and some Social Sciences in English-language contexts (21).

These differences in recommendations between disciplines suggest that a one-size-fits-all solution might not be possible or desirable when it comes to providing detailed, operationalizable RI guidance to researchers, and that further attention to disciplinary differences and considerations are needed when e.g. developing open science and data-related initiatives, policies, and standard operating procedures (SOPs), or guidelines for working collaboratively on research across disciplines. This effect may be not only due to differences in current research practices between disciplines, but also due to different histories and theories of research between disciplines, which continue to evolve.

Further research into what is considered to be important for fostering RI by societies may reveal other important differences between general and discipline-specific approaches, as well as between different discipline-specific approaches, and also between primarily social or societal and directly research-related perspectives. A better understanding of how RI is conceptualized across disciplines, and how best to operationalize this, is necessary for developing effective guidance on key 
processes in academic research and for fostering appropriate cultures of RI. Additionally, research that directly assesses the influence of the ALLEA code on the development of guidance provided by societies would provide valuable insights into whether and how the ALLEA code is already used in this process. It is important to note, however, that the availability of recommendations does not necessarily imply that researchers read and abide by them. To further investigate the value of our findings it would be interesting to explore how researchers perceive and use discipline-specific RI guidance provided by societies, and the effect of this on research practice.

\section{Strengths and Limitations}

To our knowledge, this is the first scoping review of guidance on RI from discipline-specific learned societies in Europe. The rigorous content analysis of the identified guidance documents allowed for the exploration and comparison of the content of existing guidelines between disciplines, and with the ALLEA code. The investigation was comprehensive and the sources identified and analysed are openly available for re-use. However, some relevant RI guidance may have been excluded from our analysis due to it being contained in documents that are only available for society members, rather than publicly available. For some disciplines, such as the Humanities and Social Sciences, our conclusions are likely not applicable across the whole of the discipline due to both its heterogenous nature and the fact that some sub-disciplines are relatively over-represented in our sample because of the lack of guidance provided by other sub-disciplines.

\section{Conclusions}

Considering the important role of societies in supporting and guiding researchers, we would recommend that more European discipline-specific learned societies reflect on their specific needs and develop their own RI guidance. This is particularly important for disciplines outside of the Medical and Health Sciences that have not traditionally been involved in the development of RI initiatives and whose discipline-specific perspectives might not be adequately reflected in current general guidance. Societies may also learn from one another's guidance - an example that may be applicable across disciplines is the thorough guidance on reporting and disseminating research provided in the Natural Sciences (including, for example, the distinction between honest errors and misconduct and unacceptable practices). Societies should also consider explicitly endorsing the ALLEA code and other existing guidance that reflects their needs. The development of guidance on RI from societies is particularly relevant since it appears that while the generalized guidance available in the ALLEA code addresses the performance of research, it does not extensively address social and societal aspects of research, which are likely also very relevant for RI. It may be valuable to integrate these aspects (for example, EDI) into future versions of the ALLEA code and to attend to disciplinespecific considerations, particularly when it comes to open science and data-related practices. 


\section{Acknowledgements}

The authors would like to thank Hans Ket (Vrije Universiteit Amsterdam, University Library, De Boelelaan 1117, 1081HV Amsterdam) for his help in developing the search strategy used in this study.

The authors would also like to acknowledge EnTIRE, which aims to create an online platform that makes RE and RI information easily accessible to the research community. The EnTIRE Consortium is composed of Amsterdam UMC and VU Amsterdam, Gesinn.It, KU Leuven, University of Split School of Medicine, Dublin City University, the Central European University, University of Oslo, University of Manchester, European Network of Research Ethics Committees.

\section{Funding}

This work was supported by the EnTIRE project (Mapping Normative Frameworks for EThics and Integrity of Research), which has received funding from the European Union's Horizon 2020 research and innovation program under grant agreement N 741782.

\section{Author contributions}

Conceptualization: RH, KL, LB, GW, NE

Methodology: RH, KL, IL, LB, GW, NE

Investigation: $\mathrm{RH}, \mathrm{KL}, \mathrm{IL}, \mathrm{NE}$

Data analysis: RH, KL, IL, NE

Supervision: LB, GW, NE

Writing - original draft: RH, KL, IL, NE

Writing - review \& editing: RH, KL, IL, LB, GW, NE

\section{Conflicts of interest}

The authors declare that they have no conflicts of interest.

LB is the chair of the World Conferences on Research Integrity Foundation, and was a member of the writing team for the 2018 revision of the Netherlands Code of Conduct for Research Integrity.

\section{Data and materials availability}

All data are available in the main text, supplementary files, or supporting data files here: https://osf.io/7ytch/. 


\section{REFERENCES}

(1) Ioannidis, J. P. A. (2005) 'Why Most Published Research Findings Are False', PLoS Med, 2/8: e124. doi:10.1371/journal.pmed.0020124

(2) Baker, M. (2016) '1,500 scientists lift the lid on reproducibility', Nature, 533: 452-4. doi:10.1038/533452a

(3) Bouter, L. M., Tijdink, J., Axelsen, N., Martnson, B. C., ter Riet, G. (2016) 'Ranking major and minor research misbehaviors: results from a survey among participants of four World Conferences on Research Integrity', Research Integrity and Peer Review, 1/17. doi:10.1186/s41073-016-0024-5

(4) Fanelli, D. (2009) 'How Many Scientists Fabricate and Falsify Research? A Systematic Review and Meta-Analysis of Survey Data', PLoS ONE, 4/5: e5738. doi:10.1371/journal.pone.0005738

(5) Xie, Y., Wang, K., Kong, Y. (2021) 'Prevalence of Research Misconduct and Questionable Research Practices: A Systematic Review and Meta-Analysis', Science and Engineering Ethics, 27/41. doi:10.1007/s11948-021-00314-9

(6) Gopalakrishna, G., ter Riet, G., Vink, G., Stoop, I., Wicherts, J. M., Bouter, L. M. (2021) 'Prevalence of questionable research practices, research misconduct and their potential explanatory factors: a survey among academic researchers in The Netherlands', MetaArxiv, July 6. doi:10.31222/osf.io/vk9yt

(7) Editorial (2019) 'Research integrity is much more than misconduct', Nature, 570/5. doi:10.1038/d41586-019-01727-0

(8) Titus, S. L., Wells, J. A., Rhoades, L. J. (2008) 'Repairing research integrity’, Nature, 453/19. doi:10.1038/453980a

(9) Bouter, L. M. (2020) 'What Research Institutions Can Do to Foster Research Integrity', Science and Engineering Ethics, 26:2363-2369. doi:10.1007/s11948-020-00178-5

(10) Meijlgaard, N., Bouter, L. M., Gaskell, G., Kavouras, P., Allum, N., Bendtsen, A., et al. (2020) 'Research integrity: nine ways to move from talk to walk', Nature, 586:358-60. doi:10.1038/d41586-020-02847-8

(11) Moher, D., Bouter, L. M., Kleinert, S., Glasziou, P., Sham, M. H., Barbour, V., et al. (2020) 'The Hong Kong Principles for assessing researchers: Fostering research integrity', PLoS Biol, 18/7: e3000737. doi:10.1371/journal.pbio.3000737

(12) Boehme, O., Föger, N., Hiney, M., Peatfield, T., Petiet F. (2016) 'Research Integrity Practices in Science Europe Member Organisations', Science Europe. doi:10.5281/zenodo.5060196

(13) Hiney, M. (2015) 'Research Integrity: What it Means, Why it Is Important and How we Might Protect it', Science Europe. doi:10.5281/zenodo.5060050

(14) Peels, R., Bouter, L. M. (2021) 'Replication and trustworthiness', Accountability in Research. doi:10.1080/08989621.2021.1963708

(15) All European Academies (2017) 'The European Code of Conduct for Research Integrity'. ISBN:978-3-00-055767-5 
(16) Williams, C. (2007) 'Research Methods', Journal of Business \& Economic Research, 5/3. doi:10.19030/jber.v5i3.2532

(17) Yilmaz, K. (2013) 'Comparison of Quantitative and Qualitative Research Traditions: epistemological, theoretical, and methodological differences', European Journal of Education, 48/2. doi:10.1111/ejed.12014

(18) Steneck, N. H. (1994) 'Research Universities and Scientific Misconduct: History, Policies, and the Future', The Journal of Higher Education, 65/3. doi:10.2307/2943970

(19) Penders, B., Holbrook, J. B., de Rijcke, S. (2019) 'Rinse and Repeat: Understanding the Value of Replication across Different Ways of Knowing', MDPI, 7/52. doi:10.3390/publications 7030052

(20) Peels, R., Bouter, L. M. (2018) 'The possibility and desirability of replication in the humanities', Palgrave Communications, 4/1-4. doi:10.1057/s41599-018-0149-x

(21) Knöchelmann, M. (2019) 'Open Science in the Humanities, or: Open Humanities?', MDPI, 7/65. doi:10.3390/publications7040065

(22) Tricco, A. C., Lillie, E., Zarin, W., O'Brien, K. K., Colquhoun, H., Levac, D., et al. (2018) 'PRISMA extension for scoping reviews (PRISMA-ScR): checklist and explanation.' Ann Intern Med, 169(7):467-473. doi:10.7326/M18-0850

(23) OECD Research Areas. Accessible here: http://help.prodincites.com/inCites2Live/filterValuesGroup/researchAreaSchema/oecdCategoryScheme/oecd. $\underline{\mathrm{html}}$

(24) Ayres, L., Kavanaugh, K., Knafl, K. A. (2003) 'Within-Case and Across-Case Approaches to Qualitative Data Analysis', Qualitative Health Research, 13/6:871-83. doi:10.1177/1049732303013006008

(25) Moher, D., Liberati, A., Tetzlaff, J., Altman, D. G., The PRISMA Group (2009) 'Preferred Reporting Items for Systematic Reviews and Meta-Analyses: The PRISMA Statement', PLoS Med, 6/7: e1000097. doi:10.1371/journal.pmed1000097

(26) Wilkinson, M. D., et al. (2016) 'The FAIR Guiding Principles for scientific data management and stewardship', Sci. Data, 3:160018. doi:10.1038/sdata.2016.18

(27) EU General Data Protection Regulation (GDPR): Regulation (EU) 2016/679 of the European Parliament and of the Council of 27 April 2016 on the protection of natural persons with regard to the processing of personal data and on the free movement of such data, and repealing Directive 95/46/EC (General Data Protection Regulation), OJ 2016 L 119/1.

(28) World Medical Association (2013) 'Declaration of Helsinki: ethical principles for medical research involving human subjects', JAMA, 310/20:2191-4. doi:10.1001/jama

(29) Ščepanović, R., Labib, K., Buljan, I., Tijdink, J., Marušić, A. (2021) 'Practices for Research Integrity Promotion in Research Performing Organisations and Research Funding Organisations: A Scoping Review', Sci Eng Ethics, 27/1:4. doi:10.1007/s11948-021-00281-1

(30) Open Science Collaboration (2015) 'Estimating the reproducibility of psychological science', Science, 349/6251. doi:10.1126/science.aac4716

(31) Baker R. (2014) 'Codes of Conduct' In: ten Have, H. A. M. J., Gordijn, B., editors. Handbook of Global Bioethics, pp. 551-79. Dordrecht: Springer Science and Business Media 
(32) American Association for the Advancement of Science (2000) 'The Role and Activities of Scientific Societies in Promoting Research Integrity'

(33) Iverson, M., Frankel, M. S., Siang, S., (2003) 'Scientific societies and research integrity: what are they doing and how well are they doing it?' Sci Eng Ethics, 9/2:141-58. doi:10.1007/s11948003-0002-4

(34) Macrina, F. L. (2007) 'Scientific societies and promotion of the responsible conduct of research: codes, policies, and education’, Acad Med, 82/9:865-9. doi:10.1097/ACM.0b013e31812f7e58

(35) Crain, A. L., Martinson, B. C., Thrush, C. R. (2013) 'Relationships between the Survey of Organizational Research Climate (SORC) and self-reported research practices', Science and engineering ethics, 19/3:835-850. doi:10.1007/s11948-012-9409-0

(36) Haven, T., Tijdink, J., Martinson, B., Bouter, L. M., Oort, F. (2021) 'Explaining variance in perceived research misbehavior: results from a survey among academic researchers in Amsterdam', Res Integr Peer Rev, 6/7. doi:10.1186/s41073-021-00110-w

(37) Haven, T. L., Tijdink, J. K., Martinson, B. C., Bouter, L. M. (2019) 'Perceptions of research integrity climate differ between academic ranks and disciplinary fields: Results from a survey among academic researchers in Amsterdam', PLoS One, 14/1: e0210599. doi:10.1371/journal.pone.0210599

(38) Fanelli, D., Costas, R., Larivière, V. (2015) 'Misconduct Policies, Academic Culture and Career Stage, Not Gender or Pressures to Publish, Affect Scientific Integrity', PloS one, 10/6: e0127556. doi:10.1371/journal.pone.0127556

(39) Gopalakrishna, G., Wicherts, J. M., Vink, G., Stoop, I., Van den Akker, O., ter Riet, G., Bouter, L. M. (2021) 'Prevalence of responsible research practices and their potential explanatory factors: a survey among academic researchers in The Netherlands', MetaArxiv. doi:10.31222/osf.io/xsn94

(40) Moher, D., Bouter, L. M., Kleinert, S., Glasziou, P., Sham, M. H., Barbour, V., et al. (2020) 'The Hong Kong Principles for assessing researchers: Fostering research integrity', PLOS Biology, 18/7: e3000737. doi:10.1371/journal.pbio.3000737

(41) Cagan R. (2013) 'The San Francisco Declaration on Research Assessment', Disease models \& mechanisms, 6/4: 869-870. doi:10.1242/dmm.012955

(42) Bonn, N. A., Bouter, L. M. (2021) 'Research assessments should recognize responsible research practices: Narrative review of a lively debate and promising developments'. In: Valdés, E., Lecaros, J. A. (ed.) Handbook of Bioethical Decisions - Vol. II Scientific Integrity and Institutional Ethics

(43) Labib, K., Evans, N. (2021) 'Gender, diversity, and the responsible assessment of researchers', PLoS Biol, 19/4: e3001036. doi:10.1371/journal.pbio.3001036

(44) Becher, T. (1994) 'The significance of disciplinary differences', Studies in Higher Education, 19/2:151-61. doi:10.1080/03075079412331382007

(45) Okike, K., Kocher, M. S., Mehlman, C. T., Bhandarid, M. (2008) 'Industry Sponsored Research', Injury, Int. J. Care Injured, 39: 666-80. doi:10.1016/j.injury.2008.02.013

(46) Barbour, V., Bloom, T., Lin, J., Moylan, E. (2017) 'Amending published articles: time to rethink retractions and corrections?', F1000 Research, 6/1960. doi:10.12688/f1000research.13060.1 
(47) Resnik, D. B., Stewart C. N., (2012) 'Misconduct versus Honest Error and Scientific Disagreement', Accountability in Research, 19/1: 56-63. doi:10.1080/08989621.2012.650948

(48) Severin, A., Egger, M., Eve, M. P., Hürlimann, D. (2018) 'Discipline-specific open access publishing practices and barriers to change: an evidence-based review', F1000 Research, 7/1925. doi:10.12688/f1000research.17328.1 